\title{
The universal right to health care
}

\author{
José Manuel Peixoto Caldas ${ }^{1}$, Zélia Maria de Sousa Araújo Santos ${ }^{2}$
}

Forty years ago, the $30^{\text {th }}$ World Health Assembly was organized by the World Health Organization, which led the movement "Health for everybody in 2000" resulting in the elaboration of a document entitled Declaration of Alma-Ata, reaffirming the meaning of health as a fundamental human right and one of the most important global goals for social improvement ${ }^{(1)}$.

According to the Alma-Ata Declaration, the actions to reduce social inequality should be encouraged and adopted by all countries, so the proposed global targets are met, closing the gaps between underdeveloped, developing and developed countries ${ }^{(1)}$. Therefore, investment in primary care would be the key to an equitable and comprehensive health promotion through health education actions in the context of existing public health policies. The promotion of health is essential for continued economic and social development, for the maintenance of the highest level of health and well-being, and consequently for the quality of life of the people, and the maintenance of world peace.

Therefore, it is necessary to intervene in the various social, economic and cultural determinants in a systemic, systematic and integrated way to promote health, connecting with policies to combat poverty, housing conditions, employment and work, food, transportation, security, urban planning and leisure spaces. The articulation of health with social action and education, admitting health in all policies as a reference strategy will allow to leverage and create the structure to support the sustainability of a political action.

Like most Western countries, Brazil has the defense of the Social State for the serious fight against poverty and inequalities in its Magna Carta, having one of the structuring pillars of the Unified Health System in education and health.

The consolidation of the Unified Health System is based on the defense of health care, needing to implement existing health care policies and programs, in particular through the following measures: to bet on health promotion and disease control measures; to pursue positive differentiation policies targeted at the most vulnerable citizens, women of childbearing age and children, the elderly and dependents; to expand and improve the Primary Care Network; to invest in the Continuing Care Network that has to be stimulated in the community and in the periphery of the big cities to reach the homes of the elderly and dependents, integrated with the Social Action Network. Thus an environment conducive to active and healthy aging is created, which must rely on the active participation of municipalities, improving the management of human resources and the motivation of health professionals, and deepening and developing health technologies, as stated in the Constitution: "Health is the right of everyone and the duty of the State, ensured by the social and economic policies aimed at reducing the risk of disease and other diseases and universal and equal access to actions and services for their promotion, protection, and recovery"(2:180).

\section{References}

1. World Health Organization. Declaration of Alma-Ata. International Conference on Primary Health Care [Internet]. 1978 [cited 2017 Jun 17]. Available from: www.who.int/publications/almaata_declaration_en.pdf

2. Senado Federal (BR). Constituição da República Federativa do Brasil. Brasília: Senado Federal; 1988.

\footnotetext{
${ }^{1}$ Universidade do Porto, Universidade do Minho. Porto/Braga, Portugal.

${ }^{2}$ Universidade de Fortaleza. Fortaleza, CE, Brazil.

Corresponding author: José Manuel Peixoto Caldas

Center for Health Technology and Services Research. Piso 2, edifício nascente - Faculdade de Medicina da Universidade do Porto. Rua Dr. Plácido da Costa, s/n 4200-450. Porto, Portugal. E-mail: jcaldas@unifor.br
} 